\title{
Handball load and shoulder injury rate: a 31-week cohort study of 679 elite youth handball players
}

\author{
M Møller, ${ }_{1}^{1}$ R O Nielsen, ${ }^{1}$ J Attermann, ${ }^{2} \mathrm{~N}$ Wedderkopp, ${ }^{3} \mathrm{M}$ Lind, ${ }^{4} \mathrm{H}$ Sørensen, ${ }^{1}$ \\ $G$ Myklebust $^{5}$
}

- Additional material is published online only. To view please visit the journal online (http://dx.doi.org/10.1136/ bjsports-2016-096927).

${ }^{1}$ Section for Sport Science, Department of Public Health, Aarhus University, Aarhus, Denmark

${ }^{2}$ Section for Epidemiology, Department of Public Health, Aarhus University, Aarhus, Denmark

${ }^{3}$ Sports medicine clinic, Orthopedic dep., Hospital of Lillebaelt Vejle-Middelfart, Institute of Regional Health Research and Center for

Research in Childhood Health, University of Southern

Denmark, Odense, Denmark

${ }^{4}$ Division of Sports

Traumatology, Aarhus University Hospital, Aarhus, Denmark

${ }^{5}$ Oslo Sports Trauma Research Centre, Norwegian School of Sport Sciences, Oslo, Norway

\section{Correspondence to} M Møller, Department of Public Health, Section of Sport Science, Aarhus University, Aarhus C 8000, Denmark; memo@ph.au.dk

Accepted 7 December 2016

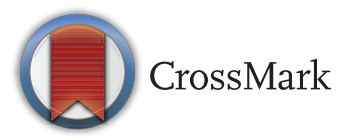

To cite: Møller M, Nielsen RO, Attermann J, et al. Br J Sports Med 2017:51:231-237

\section{ABSTRACT}

Background Knowledge of injury patterns, an essential step towards injury prevention, is lacking in youth handball.

Aim To investigate if an increase in handball load is associated with increased shoulder injury rates compared with a minor increase or decrease, and if an association is influenced by scapular control, isometric shoulder strength or glenohumeral range of motion (ROM). Methods 679 players (14-18 years) provided weekly reports on shoulder injury and handball load (training and competition hours) over 31 weeks using the SMS, phone and medical examination system. Handball load in a given week was categorised into (1) $<20 \%$ increase or decrease (reference), (2) increase between $20 \%$ and $60 \%$ and (3) increase $>60 \%$ relative to the weekly average amount of handball load the preceding 4 weeks. Assessment of shoulder isometric rotational and abduction strength, ROM and scapular control was performed at baseline and midseason.

Results An increase in handball load by $>60 \%$ was associated with greater shoulder injury rate (HR 1.91; $95 \% \mathrm{Cl} 1.00$ to $3.70, p=0.05$ ) compared with the reference group. The effect of an increase in handball load between $20 \%$ and $60 \%$ was exacerbated among players with reduced external rotational strength (HR $4.0 ; 95 \% \mathrm{Cl} 1.1$ to $15.2, \mathrm{p}=0.04)$ or scapular dyskinesis (HR $4.8 ; 95 \% \mathrm{Cl} 1.3$ to $18.3, p=0.02$ ). Reduced external rotational strength exacerbated the effect of an increase above $60 \%$ (HR 4.2; $95 \% \mathrm{Cl} 1.4$ to 12.8 , $\mathrm{p}=0.01$ ).

Conclusions A large increase in weekly handball load increases the shoulder injury rate in elite youth handball players; particularly, in the presence of reduced external rotational strength or scapular dyskinesis.

\section{INTRODUCTION}

Shoulder pain and problems represent a significant health burden in senior handball, with reported point prevalence proportions of shoulder pain between $19 \%$ and $36 \%$ at season start, ${ }^{1-3}$ and average weekly prevalence proportions of shoulder problems of $28 \%$ during the season. ${ }^{1}$ Also, shoulder pain in senior players has been reported to have an impact on the athletes' performance, training activities ${ }^{1-3}$ and daily life. ${ }^{2}$ Early identification and modification of risk factors in youth handball are thus warranted for primary prevention of the subsequent musculoskeletal disorders in adults. However, knowledge about the incidence and risk factors, the integral first step towards injury prevention, ${ }^{4}$ is lacking in this age group.

Traditionally, studies have investigated associations between non-participation-related risk factors, such as glenohumeral range of motion (ROM), ${ }^{15-8}$ shoulder strength ${ }^{17910}$ and scapular control, ${ }^{111-13}$ and risk of shoulder injuries among overhead athletes. However, sports injury research needs to move from simple analyses of risk factors and concentrate on how these factors interact among other determinants for injury. ${ }^{14}$ Injury occurrence results from a combination of possessing different risk factors and participating with these risk factors. ${ }^{15}$ On this premise, handball participation must be considered a primary risk factor for shoulder injury, while non-participation-related risk factors like strength, glenohumeral ROM and scapular control influence the amount of handball participation a player can tolerate before shoulder injury occurs. ${ }^{16}$

As a measure of participation, several studies have investigated the relationship between training load and injuries in a variety of sports other than handball, and there is growing evidence that a rapid increase in training load increases the risk of overall injury. ${ }^{17}{ }^{18}$ However, no studies have investigated if the vulnerability to a rapid increase in competition and training load is influenced by non-participation-related risk factors.

The objectives of the present study of elite adolescent handball players were to investigate if increases in weekly handball load, defined as the cumulative volume of training and competition hours, are associated with increased shoulder injury rates compared with a minor increase or decrease, and if an association is influenced by scapular control, isometric shoulder strength and glenohumeral ROM. The following a priori defined hypotheses $(\mathrm{H})$ were tested:

H1. Players who increase their handball load by more than $60 \%$ in 1 week, relative to the weekly average of the preceding 4 weeks of handball load, have an increased shoulder injury rate compared with those who increase or decrease below $20 \%$.

$\mathrm{H} 2$. The association between a moderate increase in handball load (i.e., 20-60\% load) and shoulder injury rate will be exacerbated in players with abnormal shoulder characteristics (scapular dyskinesis, reduced shoulder isometric strength and abnormal shoulder ROM). No exacerbation in the association between a high increase in weekly handball load (ie, increase above 60\%) and shoulder injury rate will exist in players with abnormal shoulder characteristics.

\section{METHODS}

\section{Study design}

In the present cohort study, we followed elite youth handball players for a full competitive handball 
season over 31 weeks from 13 October 2013 to 11 May 2014. The players were recruited from August to October 2013. Players who were not enrolled at baseline were allowed to enter the study at midseason (1 January to 1 March 2014). Methodological data from this study have previously been reported (Personal communication, 2016. M Møller, N Wedderkopp, G Myklebust, et al. The SPEx sport injury surveillance system is a feasible and valid approach to measure exposures and injuries in elite youth sport). According to the Danish Act on Research Ethics Review of Health Research Projects, The Ethics Committee of Central Denmark Region deemed the study to be exempt from full ethical review (request 89/2013) due to the study design (observational study). Permission for the study was granted by the Danish Data Protection Agency (File 2013-41-2137).

\section{Participants}

Players were recruited from all Danish First Division U-18 (range 16-18 years of age) teams and First Division U-16 (range 14-16 years of age) teams from clubs as described previously (Personal communication, 2016. M Møller, et al.). All players irrespective of current or previous shoulder pain were eligible for participation in the study. However, players were excluded if they reported a history of (1) previous shoulder surgery, (2) previous glenohumeral dislocation, (3) glenoid labrum tear, (4) rotator cuff tear or (5) fracture in the shoulder region within the previous 6 months.

\section{Outcome}

The primary outcome of interest was any new shoulder injury in the dominant arm, defined as any handball-related shoulder problem irrespective of the need for time loss or medical attention. Injury status was monitored continuously during follow-up using the SMS, phone and medical examination sports injury surveillance (SPEx) system, which has been described in detail elsewhere (Personal communication, 2016. M Møller, et al). Briefly, SPEx obtains weekly injury and handball participation information from players by SMS messaging and, in a case of injury, telephone interview, and physical examination by medical personnel within 1-2 weeks.

The outcome was based on the players' response to the following SMS question in SPEx: Have you been able to participate in handball training and match WITHOUT any physical problems (pain, discomfort, soreness, stiffness) or medical attention or illness during the past week? Injuries were classified as shoulder injury based on the follow-up telephone interview.

\section{Primary exposure}

The primary exposure of interest was the weekly change (increase or decrease) in handball playing load defined and calculated as the amount of hours of handball playing (training and match hours) ${ }^{18}$ derived from players' SMS answers in SPEx in the current week divided by the weekly average amount of playing hours during the preceding 4 weeks. ${ }^{19}$ For the analyses, we decided a priori to categorise the player's weekly reports of handball load into the following three primary exposure groups: (1) $<20 \%$ increase or decrease, (2) between $20 \%$ and $60 \%$ increase or (3) $>60 \%$ increase in handball load. The cut-off values were chosen based on the weekly mean handball playing hours (estimated to be $\sim 5$ hours/week) in injury-free weeks. Normally this is based on two to three handball-training activities and one match. An increase of 1 hour (20\% increase) would be equal to one extra weekly activity, whereas an increase of $60 \%$ would equal two or three extra weekly handball activities.

Also, 4-week average periods below 0.74 hours (equals a z-score of -2) were categorised into a fourth group so that a small increase in handball activities within a current week following a very low preceding 4-week average would be excluded from the three primary groups. ${ }^{20}$ Furthermore, the first 4 weeks of participation in the study, in which it was impossible to calculate the previous 4 weeks' average, were included in the analyses as a fifth group.

\section{Effect measure modifiers}

Factors included in the statistical analyses as modifiers of the effect of handball load on shoulder injuries were the shoulder assessments for scapular control, ${ }^{21}$ isometric rotational and abduction strength and ROM. (Personal communication, 2016. M Møller, J Attermann, G Myklebust, et al. The reliability of field-based measures of shoulder function in elite youth athletes). All strength measures were adjusted for body weight.

We created cubic splines with 4 knots (using Stata's mkspline command; Stata 14, StataCorp LP, College Station, Texas, USA) to dichotomise the continuous shoulder ROM and strength assessments. Shoulder assessments were thus included in the analyses as presented in table 1 .

At baseline, all players attended a shoulder assessment session in the players' club. We aimed to repeat all shoulder assessments for all accepting players during the midseason from 1 January to 1 March 2014.

Owing to poor reliability and agreement, the isometric strength measurement procedures were modified according to our previous results (Personal communication, 2016. M Møller, et $a l$ ). We recruited four physiotherapists to perform the shoulder assessments for each assessment parameter. The physiotherapists were blinded to the player's SMS injury and exposure reports. For each physiotherapist, we investigated the test-retest reliability on 19 male $\mathrm{u}-18$ handball players (ROM, isometric strength). Inter-reliability for scapular dyskinesis were evaluated on 20 physiotherapy students. During the main study, the physiotherapist assessing ROM stopped after baseline measurements and was replaced with another, whose reliability previously has been established. The shoulder assessment procedures, reliability results and applied statistics are described in detail in online supplementary appendices 1 and 2 .

Table 1 Cut-off values for effect measure modifiers included in the analyses

\begin{tabular}{|c|c|c|}
\hline & Reference & Abnormal \\
\hline Scapular control & Normal + Subtle & Obvious \\
\hline \multicolumn{3}{|l|}{ Rotational strength } \\
\hline ER:IR ratio dominant arm 0 rotation & $>0.75$ & $\leq 0.75$ \\
\hline ER:IR ratio dominant arm 30 rotation & $>0.75$ & $\leq 0.75$ \\
\hline \multicolumn{3}{|l|}{ Abduction strength } \\
\hline Difference dom vs non-dom & $>0.065 \mathrm{~N} / \mathrm{kg}$ & $\leq 0.065 \mathrm{~N} / \mathrm{kg}$ \\
\hline \multicolumn{3}{|l|}{ Glenohumeral range of motion } \\
\hline TROM difference dom vs non-dom & $>-10^{\circ}$ & $\leq-10^{\circ}$ \\
\hline IR difference dom vs non-dom & $>-7.5^{\circ}$ & $\leq-7.5^{\circ}$ \\
\hline ER difference dom vs non-dom & $>-10^{\circ}$ & $\leq-10^{\circ}$ \\
\hline $\begin{array}{l}\text { Dif IR dom vs non-dom:Dif ER dom vs } \\
\text { non-dom }\end{array}$ & $\leq 2.7$ & $>2.7$ \\
\hline
\end{tabular}




\section{Statistical analysis}

Cox proportional hazards regression with frailty was used to estimate hazard ratios (HRs) using calendar weeks as timescale. $^{22}$ All observations, in which the players did not report any playing time, were excluded from the analyses. The primary exposure (change in handball load) was included in the analyses as a time-dependent exposure. ${ }^{23}$ Using this approach allowed us to take the players' weekly change in handball load into account by enabling all players to transit between the three primary exposure groups by the end of each week during the 31-week follow-up using delayed entry. The categorisation of handball load and the corresponding transition between them was based solely on the player's responses to the SMS questions. Increase below 20\% or decrease in handball load was chosen as the reference group because we hypothesised such players would have the lowest injury rate. Test for no difference between survival functions in the three primary exposure groups was used to examine if a difference across the three primary exposure groups existed. Similar to change in handball load, the shoulder assessments (effect measure modifiers) were included as time-dependent covariates, providing players with shoulder follow-up measurements the possibility to transit between strata after $\sim 15$ weeks. Players not tested at follow-up kept their baseline shoulder assessment throughout the study. Handball-specific injuries unrelated to dominant shoulder injuries were included as competing risks. Players were not censored in case of an injury but were censored in case of lack of motivation, or by the end of the 31-week follow-up, whichever came first. The assumption of proportional rates was evaluated by log-minus-log plots. Shoulder injury incidence rate was calculated as the number of new and recurrent injuries during the study divided by the sum of exposure hours expressed in 1000 hours of total exposure hours (match and training). Poisson regression was used to estimate the incidence rate as a function of follow-up time in weeks and to test if this varied over time points during the season. $p$ Values were considered statistically significant at $\mathrm{p} \leq 0.05$. Medicine students, blinded to the purpose of this study, performed the data entry. All statistical analyses were unblinded conducted in Stata V.14.1 software (StataCorp, College Station, Texas, USA).

\section{RESULTS}

The details of the participant flow and the demographics of the study population have previously been reported (M Møller, et al. 2016. In review). The sample of 679 players (44\% female), representing 52 teams (of these, $37 \mathrm{U}-18$ ), reported 709 new injuries classified by telephone interviews via the SPEx system. Of these, we classified $106(14 \%)$ as shoulder injuries (85 in the dominant arm) incurred during 73546 playing hours, which corresponds to an incidence rate of 1.4 (95\% CI 1.2 to 1.7$)$ per 1000 playing hours. There was a significant change in risk of new shoulder injury during the season $(\mathrm{p}<0.001)$ (figure 1).

The risk factor analysis included 68 shoulder injuries sustained in the dominant arm (eight players and 17 injuries were excluded from the analysis after excluding observations with zero handball load the preceding week). Of the 68 injuries, six players sustained two injuries. Thirty-three out of 68 injuries $(49 \%)$ were classified as traumatic. The number of players tested and included for each effect measure modification analysis are listed in figure 2 .

Table 2 illustrates the number of weeks at risk by an increase in handball load groups according to baseline factors.

The crude analysis of the increase in handball exposure above $60 \%$ was associated with an increased shoulder injury rate compared with those increasing $<20 \%$ (table 3 ).

Scapular dyskinesis and decreased external rotational strength in $30^{\circ}$ rotation significantly modified the effect of handball load if players increased handball load between $20 \%$ and $60 \%$ (scapular dyskinesis and external rotational strength) or above $60 \%$ (external rotational strength). No significant differences across strata of shoulder ROM or abduction strength were found (table 4). We found no differences between the three primary exposure groups in any of the analyses ( $p$ values from 0.09 to 0.68 ).

\section{DISCUSSION}

The present study is the first large cohort study investigating the synergy between participation-related and non-participationrelated risk factors for shoulder injuries in sports.

A noticeable effect size $(\mathrm{HR}=1.91)$ was observed in the crude analysis. The injury rate was greater among players who increased
Figure 1 The weekly predicted incidence proportion of new shoulder injuries during a 31-week handball season in adolescent handball.

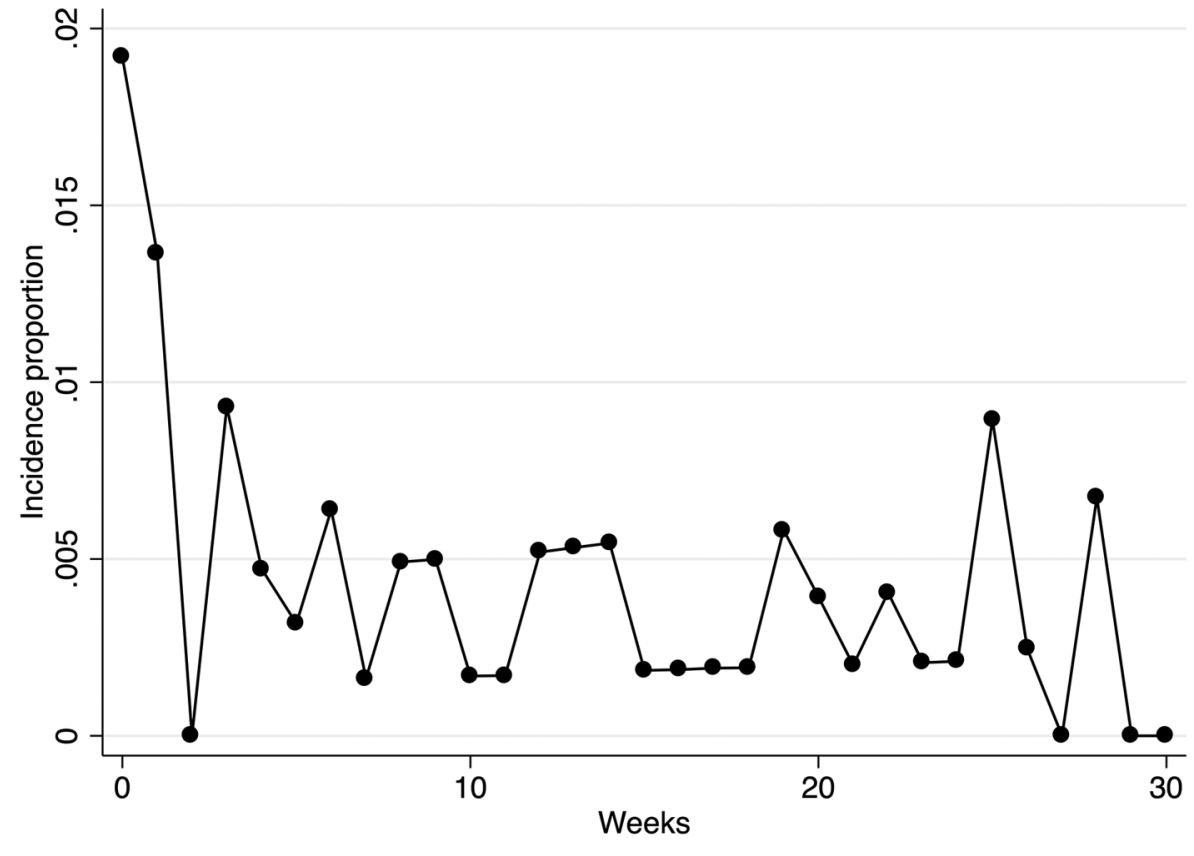


Figure 2 Numbers of players tested and included in the effect measure modification analyses. Combined scapular control=final assessments of scapular control based on the combined flexion and abduction assessment movements. *Players not tested due to (1) pain during testing, (2) rater absent the testing day, (3) other reasons. tFive players had missing values in weight.
Total number of players present at baseline testing + answered SMS messages during season $(n=679)$

\begin{tabular}{|c|c|c|c|}
\hline Rotational strength & Range of motion & Scapula control & Abduction strength \\
\hline $\begin{array}{l}\text { Tested } \\
\text { Internal } 0(n=644) \\
\text { Internal } 30(n=627) \\
\text { External } 0(n=626) \\
\text { External } 30(n=617) \\
\text { Not tested }{ }^{* \dagger} \\
\text { Internal } 0(n=35) \\
\text { Internal } 30(n=52) \\
\text { External } 0(n=53) \\
\text { External } 30(n=62)\end{array}$ & $\begin{array}{l}\text { Tested } \\
\text { Internal dom }(\mathrm{n}=548) \\
\text { External dom }(\mathrm{n}=548) \\
\text { Internal ndom }(\mathrm{n}=548) \\
\text { External } \mathrm{ndom}(\mathrm{n}=548) \\
\text { Not tested* } \\
\text { Internal dom }(\mathrm{n}=131) \\
\text { External dom }(\mathrm{n}=131) \\
\text { Internal ndom }(\mathrm{n}=131) \\
\text { External ndom }(\mathrm{n}=131)\end{array}$ & $\begin{array}{l}\text { Tested } \\
\text { Flexion }(n=656) \\
\text { Abduction }(n=653) \\
\text { Not tested } \\
\text { Flexion }(n=23) \\
\text { Abduction }(n=26)\end{array}$ & $\begin{array}{l}\text { Tested } \\
\text { Dominant }(n=651) \\
\text { Non-dominant }(n=650) \\
\text { Not tested }{ }^{* \dagger} \\
\text { Dominant }(n=28) \\
\text { Non-dominant }(n=29)\end{array}$ \\
\hline \multicolumn{4}{|c|}{ Total number of players present at follow up testing $(n=448)$} \\
\hline $\begin{array}{l}\text { Tested } \\
\text { Internal } 0(\mathrm{n}=399) \\
\text { Internal } 30(\mathrm{n}=397) \\
\text { External } 0(\mathrm{n}=387) \\
\text { External } 30(\mathrm{n}=391) \\
\text { Not tested } \\
\text { Internal } 0(\mathrm{n}=49) \\
\text { Internal } 30(\mathrm{n}=51) \\
\text { External } 0(\mathrm{n}=61) \\
\text { External } 30(\mathrm{n}=57)\end{array}$ & $\begin{array}{l}\text { Tested } \\
\text { Internal dom }(\mathrm{n}=356) \\
\text { External dom }(\mathrm{n}=355) \\
\text { Internal ndom }(\mathrm{n}=357) \\
\text { External ndom }(\mathrm{n}=357) \\
\text { Not tested* } \\
\text { Internal dom }(\mathrm{n}=92) \\
\text { External dom }(\mathrm{n}=93) \\
\text { Internal ndom }(\mathrm{n}=91) \\
\text { External ndom }(\mathrm{n}=91)\end{array}$ & $\begin{array}{l}\text { Tested } \\
\text { Flexion }(n=402) \\
\text { Abduction }(n=407) \\
\text { Not tested } \\
\text { Flexion }(n=46) \\
\text { Abduction }(n=41)\end{array}$ & $\begin{array}{l}\text { Tested } \\
\text { Dominant }(n=396) \\
\text { Non-dominant }(n=399) \\
\text { Not tested } \\
\text { Dominant }(n=52) \\
\text { Non-dominant }(n=49)\end{array}$ \\
\hline \multicolumn{4}{|c|}{ Excluded from analysis as they did not report any handball participation $(n=8)$} \\
\hline $\begin{array}{l}\text { Analysed } \\
\text { Baseline } \\
\text { EXT:INT } 0(n=614) \\
\text { EXT:INT } 30(n=604) \\
\text { Follow up } \\
\text { EXT:INT } 0(n=381) \\
\text { EXT:INT } 30(n=384)\end{array}$ & $\begin{array}{l}\text { Analysed } \\
\text { Baseline } \\
\text { External } \\
\text { Internal } \operatorname{dif}(\mathrm{n}=543) \\
\text { TROM dif }(\mathrm{n}=543) \\
\text { INT dif: } \mathrm{EXT} \operatorname{dif}(\mathrm{n}=543) \\
\text { Follow up } \\
\text { External } \operatorname{dif}(\mathrm{n}=351) \\
\text { Internal } \operatorname{dif}(\mathrm{n}=352) \\
\text { TROM dif }(\mathrm{n}=351) \\
\text { INT dif:EXT dif }(\mathrm{n}=351)\end{array}$ & $\begin{array}{l}\text { Analysed } \\
\text { Baseline } \\
\text { Combined scapula } \\
\text { control }(\mathrm{n}=648) \\
\text { Follow up } \\
\begin{array}{l}\text { Combined scapula } \\
\text { control }(\mathrm{n}=393)\end{array}\end{array}$ & $\begin{array}{l}\text { Analysed } \\
\text { Baseline } \\
\text { Difference }(\mathrm{n}=633) \\
\text { Follow up } \\
\text { Difference }(\mathrm{n}=384)\end{array}$ \\
\hline
\end{tabular}

Table 2 Number (\% of total) of weeks at risk included in the analysis by increase in handball load groups* and baseline factors in 671 youth handball players (14 684 weeks at risk)

\begin{tabular}{|c|c|c|c|c|c|c|}
\hline & \multicolumn{6}{|c|}{ Exposure groups of handball load* } \\
\hline & $<20 \%$ & $20-60 \%$ & $>60 \%$ & $<-2$ SD & 4 weeks & Total \\
\hline \multicolumn{7}{|l|}{ Sex } \\
\hline Boys ( $n=367$ ) & $3854(26)$ & $1317(9)$ & $1295(9)$ & $1279(9)$ & $165(1)$ & $7910(54)$ \\
\hline Girls $(n=304)$ & $3407(23)$ & $1223(8)$ & $944(6)$ & $1072(7)$ & $128(1)$ & $6774(46)$ \\
\hline \multicolumn{7}{|l|}{ Age group } \\
\hline U16 (n=239) & $2710(18)$ & $901(6)$ & $796(5)$ & $113(1)$ & $842(6)$ & $5362(37)$ \\
\hline U18 $(n=432)$ & $4551(31)$ & $1639(11)$ & $1443(10)$ & $180(1)$ & $1509(10)$ & $9322(63)$ \\
\hline \multicolumn{7}{|l|}{ Player position } \\
\hline Back players $(n=303)$ & $1831(12)$ & $639(4)$ & $560(4)$ & $70(0.5)$ & $578(4)$ & $3678(25)$ \\
\hline Wing players ( $n=168$ ) & $3152(21)$ & $1221(8)$ & $973(7)$ & $130(1)$ & $1061(7)$ & $6437(44)$ \\
\hline Line players $(n=102)$ & $1194(8)$ & $432(3)$ & $389(3)$ & $40(0)$ & $357(2)$ & $2412(16)$ \\
\hline Goal keepers $(n=97)$ & $1084(7)$ & $348(2)$ & $317(2)$ & $53(0.5)$ & $355(2)$ & 2157 (15) \\
\hline \multicolumn{7}{|l|}{ History of shoulder injury } \\
\hline Yes $(n=43)$ & $466(3)$ & $172(1)$ & $145(1)$ & $16(0)$ & $148(1)$ & $947(6)$ \\
\hline No $(n=628)$ & $6795(46)$ & $2368(16)$ & 2094 (14) & $277(2)$ & $2203(15)$ & $13737(94)$ \\
\hline
\end{tabular}

their handball load by more than $60 \%$ compared with those players who decreased or increased their handball load below $20 \%$. In addition, scapular dyskinesis and decreased external strength at $30^{\circ}$ rotation exacerbated the effect among players increasing in handball load to a moderate extent (20-60\%).
Our a priori hypotheses were supported by these findings. They indicate that a $60 \%$ increase in handball load can increase the shoulder injury rate even in players with normal shoulder characteristics. Also, scapular dyskinesis and reduced external rotational strength make players prone to shoulder injury at a 
Table 3 Crude analysis of the association between an increase in handball load* and risk of shoulder-related injuries in handball

\begin{tabular}{|c|c|c|c|c|c|}
\hline $\begin{array}{l}\text { Exposure group } \\
\text { of handball load* }\end{array}$ & Injuries & $\begin{array}{l}\text { Weeks } \\
\text { at risk }\end{array}$ & HR & $95 \% \mathrm{Cl}$ & p Value \\
\hline Min to $20 \%$ & 26 & 7261 & 1 (ref) & & \\
\hline $20-60 \%$ & 11 & 2540 & 1.22 & 0.62 to 2.40 & 0.57 \\
\hline$>60 \%$ & 15 & 2239 & 1.91 & 1.00 to 3.70 & 0.05 \\
\hline$<-2$ SD & 1 & 293 & 1.07 & 0.32 to 23.18 & 0.95 \\
\hline 4 weeks & 15 & 2351 & 2.70 & 0.13 to 8.58 & 0.36 \\
\hline Total & 68 & 14684 & & & \\
\hline Test for no difference & & & & & $0.14 \dagger$ \\
\hline \multicolumn{6}{|c|}{$\begin{array}{l}\text { *See the text for definition. } \\
t-2 \text { SD and 4-week groups not included. } \\
-2 S D \text {, weeks in which the } 4 \text {-week average handball load was below }-2 \text { SDs from the } \\
\text { mean; } \\
4 \text { weeks, the first } 4 \text { weeks of study, increase in handball load calculations not } \\
\text { possible. }\end{array}$} \\
\hline
\end{tabular}

moderate increase in handball load, compared with players with normal scapular control and external rotational strength. Importantly, though, if players with scapular dyskinesis or reduced external rotation strength do not increase their handball load by more than $20 \%$, they are not more predisposed to shoulder injury compared with players with normal characteristics. These findings suggest that large weekly increases in handball load are the primary risk factor for shoulder injuries in youth handball. However, reduced external rotational strength also accentuated the effect of handball load on shoulder injury rate at an increase in handball load above $60 \%$, which may indicate that the cut point between a moderate and high increase in handball load should exceed $60 \%$.

We found no significant differences across strata of shoulder abduction and ROM measurements. In fact, there were very small differences in ROM between dominant and non-dominant shoulders (results not shown), and it is likely that the normal soft tissue or/and bony adaptations to the repeated throwing reported in senior female handball ${ }^{2}$ and from a variety of other sports $^{824-28}$ are not yet present in youth handball players.

In general, our results cannot be compared with those of other studies investigating non-participation-related risk factors, as to the best of our knowledge no other studies in overhead sport have examined the synergy between training and competition load and non-participation-related risk factors, but instead compare the crude association between non-participation-related risk factors and the subsequent risk of injury, or do not take sport participation into account. ${ }^{15-13} 29$

The reported shoulder injury rate of 1.4 per 1000 playing hours was 2.5 times higher (incidence rate ratio 2.5 , 95\% CI 1.6 to 4.0 ) than the reported shoulder injury rate of 0.6 per 1000 playing hours previously reported in a similar population using a time-loss definition as injury outcome. ${ }^{30}$

\section{Methodological considerations}

The present study's major strength is the applied statistical analysis that takes the dynamic changing nature of risk factors into account. ${ }^{15}$ However, our analyses are limited by the number of events that are required to perform these analyses. The effect modifier analyses were further limited by the fact that not all players were tested, which reduced the number of included injuries.

\section{Information problems}

Recall bias is limited for injury and handball load reports owing to the high weekly response rates (88-97\%) to the SMS part in
SPEx and the 95\% follow-up rates by telephone classification. Still, the comparisons between injury outcomes from SPEx and on-field and medical observers demonstrated that $10 \%$ of all injury registrations were missed by the SPEx sports injury surveillance system, indicating a risk of misclassification. Furthermore, although most players responded rapidly to the SMS messages, it is evident that some players reported their injuries with a delay of 1 week or more (Personal communication, 2016. M Møller, N Wedderkopp, G Myklebust, et al. The SPEx sport injury surveillance system is a feasible and valid approach to measure exposures and injuries in elite youth sport). This is particularly relevant in the applied analyses where the change in handball load the week before an injury was investigated. However, we find it plausible to assume that the potential misclassification of injury status is similar across handball load groups. If this is the case, such non-differential misclassification may lead to bias towards null (no difference in shoulder injury rate between handball load groups). Hence, the association between change in handball load and shoulder injuries is underestimated.

As regards the registration of handball load, we believe that the use of the SPEx sports injury surveillance system ensures more accurate results than would have been obtained in studies analysing handball exposure at a group level using observational methods. Still, there is a risk that some players have been misclassified into wrong weekly exposure groups during the season. However, the players were unaware of the purpose of the analyses. Consequently, they likely have not been motivated to either under-report or over-report their shoulder injuries. Any potential misclassification must thus be non-differential leading to an underestimation of the association between change in handball load and shoulder injuries.

The fact that the same physiotherapists, except for ROM, assessed the players' shoulder profiles twice during the study in order to accommodate the changing injury risk profile throughout the season was a key strength of the present study. The cut points in which the continuous strength and ROM measurements could be translated into dichotomous risk factors were defined in this study. These cut-off values would determine if a player was at increased risk of injury or not. It should be noted that there is a high risk of categorising players into wrong exposure group due to random measurement error, even though, we found no systematic bias and less wide limits of agreement for the newly developed strength and ROM assessments than previously reported (see online supplementary appendix 2). The physiotherapists were blinded to previously reported injuries before the follow-up, and also to the selected cut points. This limits the risk that the physiotherapists unintentionally have influenced the measurements in a particular direction. Therefore, the potential misclassification of the shoulder assessments may have been non-differential leading to an underestimation between the sports participation, the given effect modifier and the shoulder injury.

The above-mentioned potential misclassifications might have prevented us from detecting other associations between handball load and shoulder injury (type 2 error).

\section{Selection problems}

$\mathrm{U}-16$ teams were invited to participate in this study only if their U-18 team accepted to take part in this research. Consequently, there is a possibility that the U-16 players included in this study were from more elite clubs, and their handball load habits might not reflect those $\mathrm{u}-16$ players at less elite clubs. Less elite clubs may also have limited recourses, lack of access to medical 
Table 4 The association between increase* in handball load and risk of shoulder-related injuries in youth handball stratified by shoulder assessments

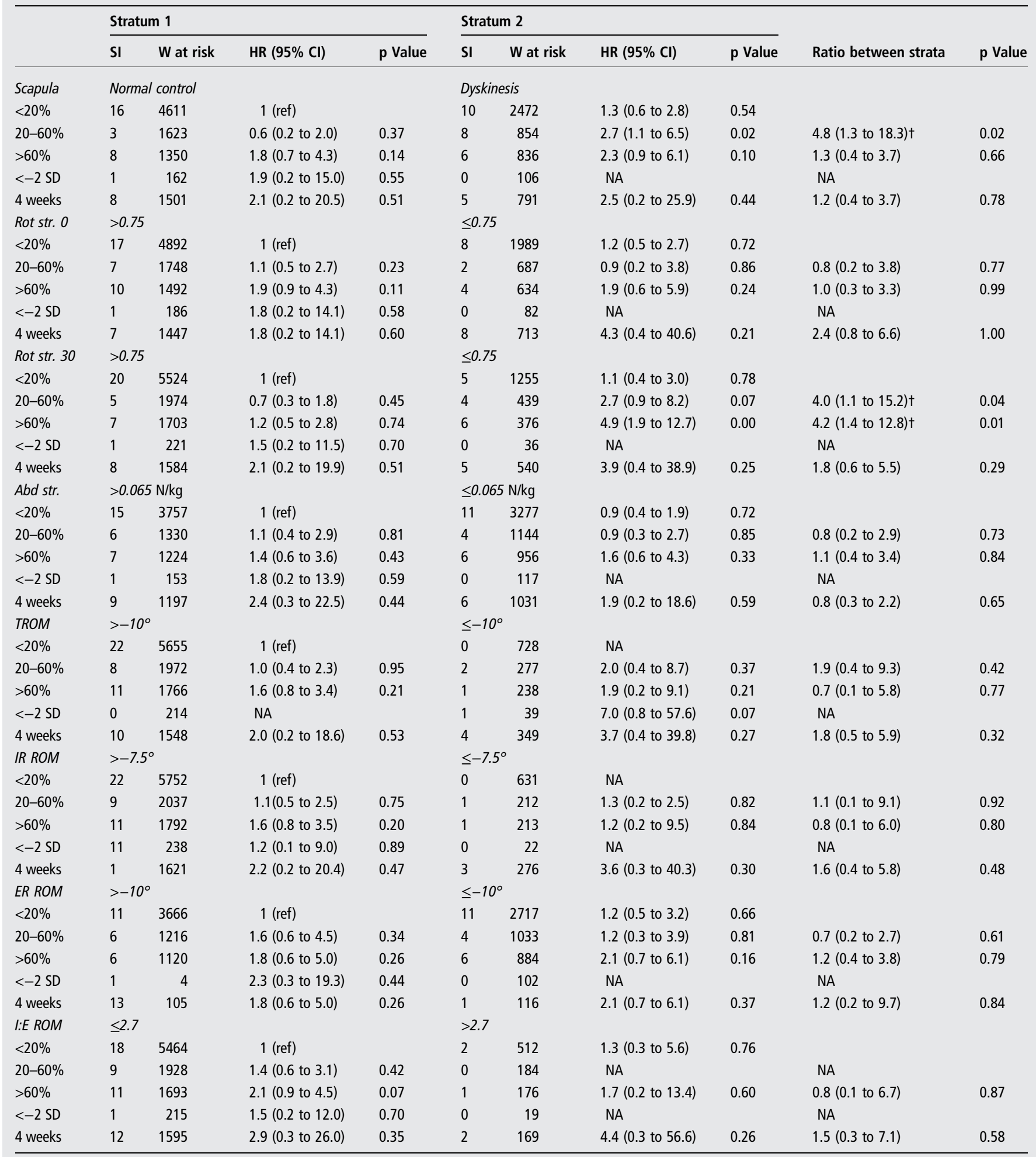

The total number of injuries was 68 and the total number of weeks at risk was 14684 .

* See the text for definition of progression.

tDenotes that the shoulder test (scapula control and isometric rotational strength at $30^{\circ}$ rotation) significantly modifies the effect of workload ratio on handball-specific shoulder injuries.

-2 SD, weeks in which the 4-week average handball load was below -2 SDs from the mean; 4 weeks, the first 4 weeks of study, increase in handball load calculations not possible; Abd str., isometric abduction strength difference between dominant and non-dominant arm; ER ROM, external range of motion difference between dominant and non-dominant arm; I:E ROM, The ratio of the difference between internal rotation dominant arm vs. internal rotation non-dominant arm and difference external rotation dominant arm vs. external rotation non-dominant arm; IR ROM, internal range of motion difference between dominant and non-dominant arm; Rot str. 0 , external:internal ratio rotational strength at $0^{\circ}$ rotation; Rot str. 30 , external:internal ratio rotational strength at $30^{\circ}$ rotation; SI, shoulder injury; TROM, total range of motion difference between dominant and non-dominant arm; W, weeks. 
and support staff. Therefore, these players may sustain more injuries than the $\mathrm{u}-16$ players linked with an elite club participating in this study. This potentially skewed 'healthy player' selection might have led to selection bias in this age group.

We found no significant differences in hazards for injuries between players who attended the shoulder assessments and players who did not, limiting the risk of skewed selection, and thus selection bias.

\section{Confounding}

There is a high risk of known and unknown confounding due to the inherent nature of the prospective study design. The potential confounders were, a priori, assumed to be playing position and previous injuries. However, due to the low frequency of shoulder injuries reported in the present study, it was not possible to control for these factors within the analyses, and this is a limitation of this study.

\section{CONCLUSION}

Our findings demonstrated that the shoulder injury rate in elite youth handball players was nearly twice as high in the week following a $60 \%$ or greater increase in handball load when compared with a decrease or a small-to-moderate increase in handball load $<20 \%$.

In addition, the findings showed that an effect of a moderate increase between $20 \%$ and $60 \%$ in handball load was exacerbated by the presence of reduced external rotational strength or scapular dyskinesis and that reduced shoulder external rotational strength also exacerbated the effect of large increases in handball load above 60\%. Finally, we found 2.5 times higher shoulder injury incidence rate among 14-18-year-old handball players than previously reported.

\section{What are the findings?}

- Large increase in weekly handball load is associated with an increased rate of shoulder injuries in youth handball.

- Scapular dyskinesis and reduced external rotational strength reduce the amount of increase in handball load a player can tolerate before injury occurs.

- Shoulder injury incidence in youth handball is more than twice as high as previously reported.

\section{How might it impact on clinical practice in the future?}

Coaches and support personnel should monitor youth handball players' handball load on an individual basis. Concerted efforts should be made to avoid rapid increases in handball load. Particularly for players with scapular dyskinesis and reduced strength, because players with these certain characteristics may be more vulnerable to shoulder injury already at a moderate increase in handball load.

Twitter Follow Merete Møller @Merete_Moller and Rasmus $\varnothing$ Nielsen @RUNSAFE_Rasmus

Acknowledgements The authors are grateful to all the players, coaches, physiotherapists, doctors and students for their participation in this study, and thank
The Danish Rheumatism Association and Team Danmark for their generous economic support of this study.

Contributors MM and RON formulated the initial concept of the manuscript. All authors contributed to the manuscript preparation. MM was responsible for data collection, data analysis and the overall content.

Funding The Danish Rheumatism Association (grant number R114-A2678), Team Danmark.

Competing interests None declared.

Ethics approval According to the Act on Research Ethics Review of Health Research Projects, The Ethics Committee of Central Denmark Region deemed the study to be exempt from full ethical review (request 89/2013) due to the study design (observational study). Permission for the study was granted by the Danish Data Protection Agency (File no 2013-41-2137).

Provenance and peer review Not commissioned; externally peer reviewed.

Data sharing statement All data are available on request. All personally identifiable information will be deleted or anonymised before data transfer.

\section{REFERENCES}

1 Clarsen B, Bahr R, Andersson SH, et al. Reduced glenohumeral rotation, external rotation weakness and scapular dyskinesis are risk factors for shoulder injuries among elite male handball players: a prospective cohort study. Br I Sports Med 2014;48:1327-33.

2 Myklebust G, Hasslan L, Bahr R, et al. High prevalence of shoulder pain among elite Norwegian female handball players. Scand J Med Sci Sports 2013;23:288-94.

3 Mohseni-Bandpei MA, Keshavarz R, Minoonejhad H, et al. Shoulder pain in Iranian elite athletes: the prevalence and risk factors. J Manipulative Physiol Ther 2012;35:541-8

4 Finch C. A new framework for research leading to sports injury prevention. I SCi Med Sport 2006:9:3-9; discussion 10.

5 Shanley E, Kissenberth MJ, Thigpen CA, et al. Preseason shoulder range of motion screening as a predictor of injury among youth and adolescent baseball pitchers. J Shoulder Elbow Surg 2015;24:1005-13.

6 Shanley E, Rauh MJ, Michener LA, et al. Shoulder range of motion measures as risk factors for shoulder and elbow injuries in high school softball and baseball players. Am J Sports Med 2011;39:1997-2006.

7 Tyler TF, Mullaney MJ, Mirabella MR, et al. Risk factors for shoulder and elbow injuries in high school baseball pitchers: the role of preseason strength and range of motion. Am J Sports Med 2014;42:1993-9.

8 Wilk KE, Macrina LC, Fleisig GS, et al. Correlation of glenohumeral internal rotation deficit and total rotational motion to shoulder injuries in professional baseball pitchers. Am J Sports Med 2011;39:329-35.

9 Byram IR, Bushnell BD, Dugger K, et al. Preseason shoulder strength measurements in professional baseball pitchers: identifying players at risk for injury. Am J Sports Med 2010;38:1375-82.

10 Edouard $\mathrm{P}$, Degache $\mathrm{F}$, Oullion $\mathrm{R}$, et al. Shoulder strength imbalances as injury risk in handball. Int J Sports Med 2013;34:654-60.

11 Laudner KG, Myers JB, Pasquale MR, et al. Scapular dysfunction in throwers with pathologic internal impingement. J Orthop Sports Phys Ther 2006;36:485-94.

12 Myers JB, Oyama S, Hibberd EE. Scapular dysfunction in high school baseball players sustaining throwing-related upper extremity injury: a prospective study. J Shoulder Elbow Surg 2013;22:1154-9.

13 Struyf F, Nijs J, Meeus $M$, et al. Does scapular positioning predict shoulder pain in recreational overhead athletes? Int J Sports Med 2014:35:75-82.

14 Bittencourt NF, Meeuwisse WH, Mendonca LD, et al. Complex systems approach for sports injuries: moving from risk factor identification to injury pattern recognition-narrative review and new concept. Br J Sports Med 2016;50:1309-14.

15 Meeuwisse WH, Tyreman $\mathrm{H}$, Hagel $B$, et al. A dynamic model of etiology in sport injury: the recursive nature of risk and causation. Clin J Sport Med 2007;17:215-9.

16 Malisoux L, Nielsen RO, Urhausen A, et al. A step towards understanding the mechanisms of running-related injuries. I Sci Med Sport 2015;18:523-8.

17 Drew MK, Finch CF. The relationship between training load and injury, illness and soreness: a systematic and literature review. Sports Med 2016:46:861-83.

18 Soligard T, Schwellnus M, Alonso JM, et al. How much is too much? (Part 1) International Olympic Committee consensus statement on load in sport and risk of injury. Br J Sports Med 2016;50:1030-41.

19 Malisoux L, Frisch A, Urhausen A, et al. Monitoring of sport participation and injury risk in young athletes. J Sci Med Sport 2013;16:504-8.

20 Hulin BT, Gabbett TJ, Lawson DW, et al. The acute:chronic workload ratio predicts injury: high chronic workload may decrease injury risk in elite rugby league players. Br J Sports Med 2016;50:231-6.

21 McClure $\mathrm{P}$, Tate AR, Kareha $\mathrm{S}$, et al. A clinical method for identifying scapular dyskinesis, part 1: reliability. J Athl Train 2009;44:160-4.

22 Bull K, Spiegelhalter DJ. Survival analysis in observational studies. Stat Med 1997:16:1041-74. 


\section{Original article}

23 Nielsen Rø, Malisoux L, Møller M, et al. Shedding light on the etiology of sports injuries: a look behind the scenes of time-to-event analyses. J Orthop Sports Phys Ther 2016;46:300-11.

24 Almeida GP, Silveira PF, Rosseto NP, et al. Glenohumeral range of motion in handball players with and without throwing-related shoulder pain. J Shoulder Elbow Surg 2013;22:602-7.

25 Ellenbecker TS, Roetert EP, Bailie DS, et al. Glenohumeral joint total rotation range of motion in elite tennis players and baseball pitchers. Med Sci Sports Exerc 2002;34:2052-6

26 Ellenbecker TS, Roetert EP, Piorkowski PA, et al. Glenohumeral joint internal and external rotation range of motion in elite junior tennis players. $J$ Orthop Sports Phys Ther 1996;24:336-41.
27 Reeser JC, Joy EA, Porucznik CA, et al. Risk factors for volleyball-related shoulder pain and dysfunction. PM R 2010;2:27-36.

28 Trakis JE, McHugh MP, Caracciolo PA, et al. Muscle strength and range of motion in adolescent pitchers with throwing-related pain: implications for injury prevention. Am J Sports Med 2008;36:2173-8.

29 Amin NH, Ryan J, Fening SD, et al. The relationship between glenohumeral internal rotational deficits, total range of motion, and shoulder strength in professional baseball pitchers. J Am Acad Orthop Surg 2015;23:789-96

30 Moller M, Attermann J, Myklebust G, et al. Injury risk in Danish youth and senior elite handball using a new SMS text messages approach. Br J Sports Med 2012:46:531-7. 